\title{
KNOWLEDGE EXCHANGE IN A SUPPLY CHAIN CONTEXT
}

\author{
Laurent Buzon, Aziz Bouras, Yacine Ouzrout \\ Laboratoire PRISMa / CERRAL \\ Université Lumière Lyon 2 \\ [firstname].[lastname]@univ-lyon2.fr \\ FRANCE
}

\begin{abstract}
The virtual alliance between supply chain actors enables to create new links to better share information and knowledge. There are already some methods and approaches specifically designed to share and exchange this knowledge in local areas of the supply chain. In this paper, we are interested in treating this issue in a global perspective andfocuses also on the classification of the knowledge according to some criteria as knowledge structure, knowledge type, knowledge nature, etc. The dynamic of the knowledge is introduced within an organizational learning perspective between the supply chain actors.
\end{abstract}

\section{INTRODUCTION}

The collaboration in supply chain management aims at increasing utilization and synchronization of the chain resulting in tangible benefits for each participating companies (Anand, 2000 and Hall, 1998). Within this context, the supply chain concept can be seen as collaborative network of organizations working together to maximize the value of a product to the final client. To be able to reduce conflict within this complex system, companies need to have common goals, have clearly defined domains and especially have an uniform understanding of situations (Taudes, 2002). Therefore, the sharing of knowledge and competencies amongst companies is a vital tool of competition (Dyer, 1996).

In this paper, we adopt a view where the knowledge circulates with the help of each supply chain actors only communicating with their closest neighbours in the chain. The proposed primary study consists in a new configuration of known concepts and approaches in order to design a prototype aiming at sharing and exchanging knowledge between the supply chain actors. 
We describe in the first part of the paper, the knowledge exchange context within a supply chain network. In a second part, we propose a classification to structure and to map this knowledge. Then, we discuss the knowledge dynamics to manage the knowledge creation and diffusion.

\section{THE KNOWLEDGE EXCHANGE}

The ability to make fast and rapid decisions constitutes a competitive advantage (Davenport, 1998) by reducing the cycle time, by increasing the flexibility to respond to change in customer demand which can enhance customer satisfaction and increase market share (Romano, 2003). In this way, enterprises exchange knowledge to improve the global value carry out by the supply chain (Larsson, 1998). They exchange knowledge : product features, process information, best practices, allowed adjustments, dictionaries, etc., as we can see in the following figure.

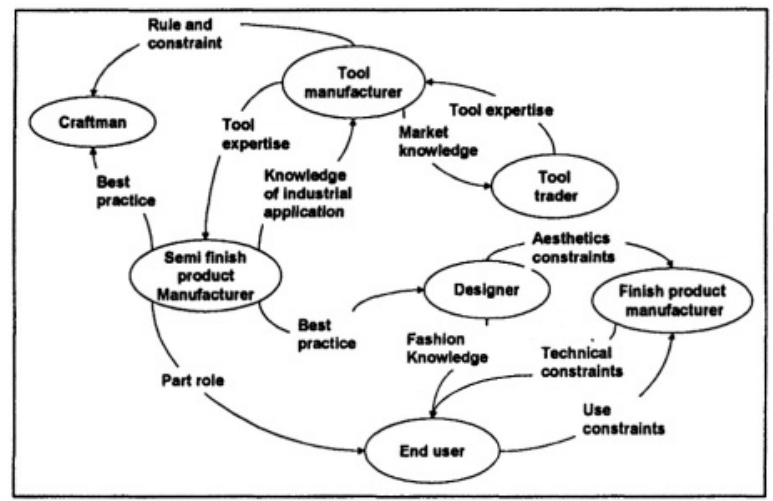

Figure 1 -Knowledge exchanges in an example of a supply chain network

In a first step, we have made a study of the supply chain approaches to understand how the knowledge is exchanged in the supply chain. This, resulted in several approaches that are able to allow specific knowledge transfer as PLM (Product Lifecycle Management) that covers the product information and constraints along its lifecycle, ERP (Enterprise Resource Planning) that deals with the organization processes, SRM (Supply Resource Management) that manages the upstream chain, the parts and products flows and CRM (Customer Relationship Management) that is used to anticipate and to meet the customer needs.

All these solutions communicate (as shown in the second figure) and permit to understand the partner needs in order to maximize the entire supply chain performance. For example, they anticipate and optimize the production planning as following : The CRM gives the sales forecast and the ERP and SRM tools deduce the production path and synchronize the partners production flows (Ovalle, 2003). However, these tools only automate routine knowledge exchange and exchange supply chain knowledge to answer punctual and specific needs. 


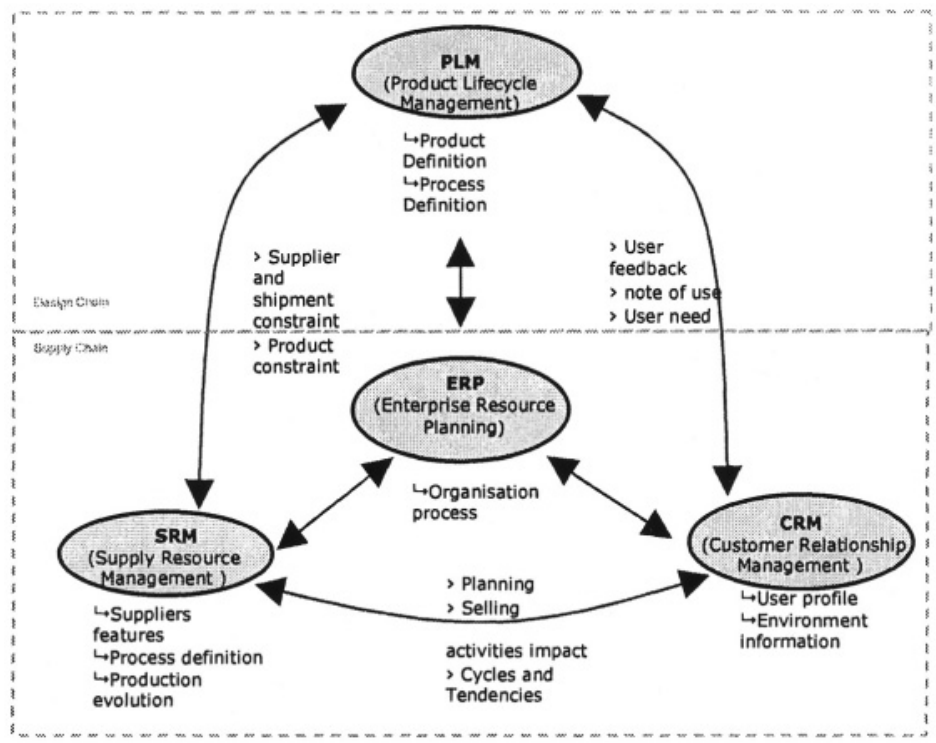

Figure 2-Supply chain tools network.

In a second step, to structure and facilitate the knowledge exchange, we propose a classification that helps the network actors to be aware of their knowledge and their asset complementarities. This classification integrates a new configuration of usual concepts of the knowledge management domain to map the knowledge structure and location.

\section{KNOWLEDGE CLASSIFICATION}

We elaborate a supply chain knowledge classification to structure and to organize the knowledge according to its potential use in the supply chain domain. This classification is composed of three dimensions. The first proposes to focus on the nature of the knowledge according to the supply chain point of view. The second one deals with its structure, giving a temporal and abstracted perspectives in order to indicate the problem type to solve. The third dimension indicates the state and the form of the knowledge to manage the knowledge system and its dynamic.

\subsection{Knowledge nature}

The supply chain can be seen as organizations network having more or less degrees of collaboration in an artefact production process made up of goods and services. Our aim is to propose a classification of the knowledge that corresponds to this vision and to the supply chain actors culture. This is why we base it on process (Operations) delivering function in a fluctuant environment (Context) like Huizenga and Den Hartog (1998).

- Contextual knowledge about the market environment, supplier and customer needs; 
- Operational knowledge linked to the firm organizational and technical processes;

- Functional knowledge, knowledge within disciplines specialities;

The contextual knowledge represents the network environment in the supply chain as the market or the supplier of the network. The operational knowledge corresponds to the processes across the supply chain shows the elements that impact directly the final artefact value. It also describes the partners features as capabilities and work practices. And the functional knowledge deals with the academic and general knowledge concerning a specific domain.

These three categories describe the nature and domain of knowledge and show to the user the circumstances where this knowledge can be applied in a supply chain perspective.

For example, downstream organizations in the chain like distributors and retailers know better the market than the production processes and consequently have contextual knowledge available. However, these organizations feel higher need for operational knowledge of processes and products.

\subsection{The knowledge structure}

The representative forms of knowledge follow the Wiig (1993) model to facilitate the users tasks by determining the knowledge application possibilities and their abstraction level. This model is well adapted to the supply chain because the Wiig classification allows to describe the time perspectives as forecast or plan, and multiple user point of view (buyer, seller, supplier, ...). Moreover, it distinguishes the methodological aspects (theory) and the factual aspects (empiricism).

We retain the four representative forms of knowledge in the Wiig classification :

Static perspective:

- Factual knowledge : Facts, datas,

- Conceptual knowledge : Perspectives, concept, gestalts

Dynamic perspective (with a time perspective):

- Expectational knowledge : Judgements, hypothesis, expectations

- Methodological knowledge : Reasoning, strategies, methodologies

The conceptual knowledge represents the abstract level of the knowledge as an ontology domain which provides a vocabulary of concepts. Each concept is explicitly defined and has processing semantics. This ontology helps to define a generic conceptualization, shared by the supply chain actors. The shared and common domain concepts help both people and machines to communicate for different points of view (Fensel and al, 2002).

\subsection{The Knowledge typology}

Polanyi (1966) classified knowledge into two categories to indicate its knowledge accessibility level.

- Tacit knowledge : It is highly personal and hard to formalize, making it difficult to communicate or share with others. Subjective insights, intuitions and hunches fall into this category of knowledge.

- Explicit knowledge : Codified knowledge that can be transmitted in formal, systematic language. It is discrete or 'digital'. It is captured in records of the 
past such as libraries, archives and databases and is assessed on a sequential basis.

The tacit knowledge is harder to manage because it do not lie in documents but in the individual brain (Nonaka, 1998). We propose to link the explicit knowledge to documents and the tacit knowledge to individuals.

\subsection{The knowledge cube}

The result of the discussed classification is a knowledge cube (figure 3) where the principal knowledge resources can be structured.

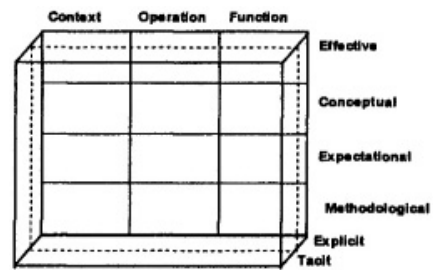

Figure 3 - the knowledge cube classification

The knowledge cube classification can be divided in tow sub-cubes, one for the tacit knowledge which is hard to formalise and the other for the explicit knowledge as we can see in the following figure. This partition permits to propose a tool that combine the explicit dimension that link to document, repository, multimedia base, etc., and the tacit dimension which link to expert or group of experts as community of practices.

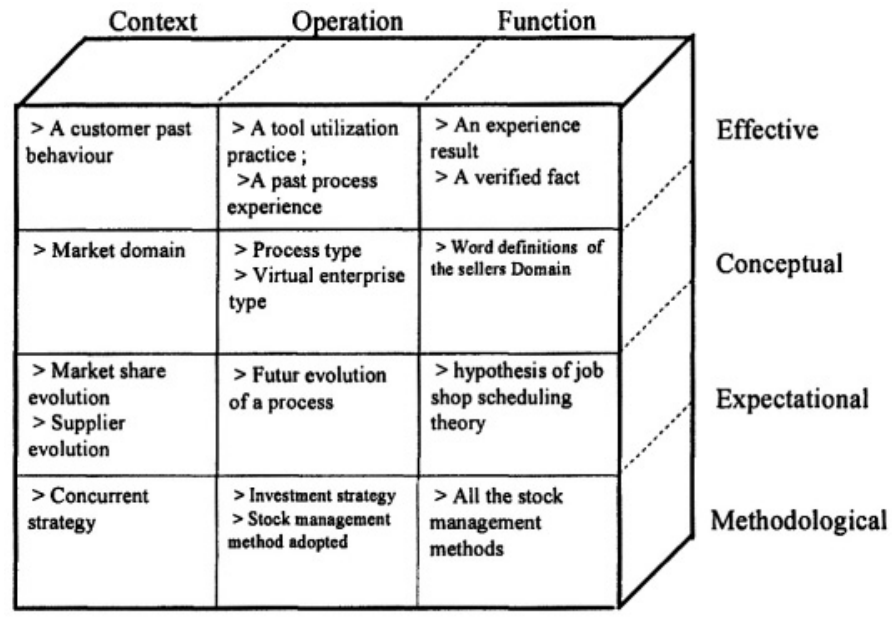

Figure 4 - An example of the explicit knowledge classification

In order to facilitate its use, the explicit knowledge can be formalized in any forms as needed, as with SADT, UML or GRAI, etc., with links to the related documents that can be easily created, manipulated and consulted (Buzon and al, 2003). 
The structure of knowledge is not static, it evolves with the organizational learning degree of the network. We have studied the knowledge dynamic to understand how the knowledge evolution path in the network can create or upgrade knowledge.

\section{THE KNOWLEDGE DYNAMIC}

In bringing together firms with different skills and knowledge bases, the supply chain creates learning opportunities for the partner firms (Gulati, 1999). In this context, we must enable the organizational learning to favour the adaptation of the network to its fluctuant environment described in the contextual knowledge.

Some learning literature (Inkpen, 1998) argues that collaboration not only transfers existing knowledge among organizations, but also facilitates the creation of new knowledge and produce synergistic solutions. The knowledge creation could be new practices, cultural change, ontology, new expertise, new combination of resources applying in the supply chain. The first knowledge creation corresponds logically to the processes of coordination of the virtual organization (Parenta, 2003). Fong (2003) distinguishes three modes of knowledge creation : Knowledge sharing, knowledge integration and collective project learning.

To capture these dynamic movements of knowledge, we adopt the Nonaka (1995) model because his work has become widely accepted in a variety of management fields such as organizational learning, joint ventures, new product development, and information technology.

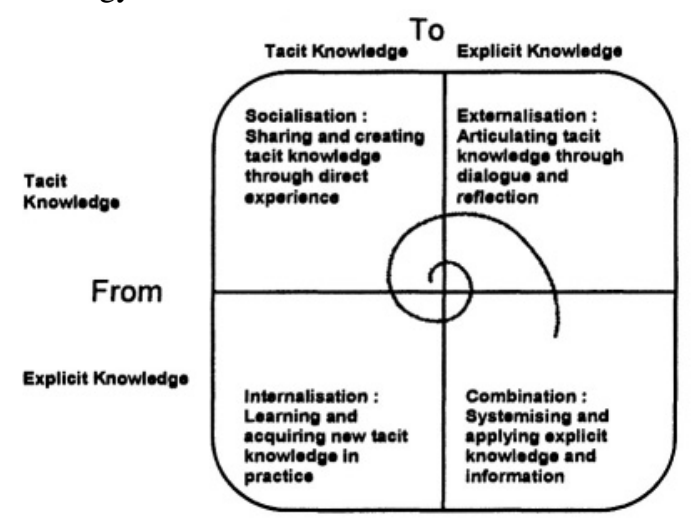

Figure 5 - The organizational knowledge spiral (Nonaka and Konno, 1998)

As the knowledge spiral upward in the organization, individuals interact with each other and with their environment (organisation, client, supplier , ..). These interactions and these connections are critical for the interorganizational learning. They create the potential for individuals to share their observation and experiences and provide a basis for transforming individual knowledge to organizational knowledge (the knowledge may also be further developed and moves upward in the organization). The cube classification, presenting the knowledge in a common understanding with several points of views that creates links among individuals. It also helps to better understand new ideas and new practices that create incentives for 
innovative behaviour to further enhance the technological capabilities of the supply chain actors.

In our classification, the "Expectational" knowledge becomes the "Effective" knowledge that validates judgement or hypothesis. The Functional knowledge is in a long term perspectives whereas the Contextual and the Operational knowledge can become quickly obsolete in fluctuant environment and rapid technical changes.

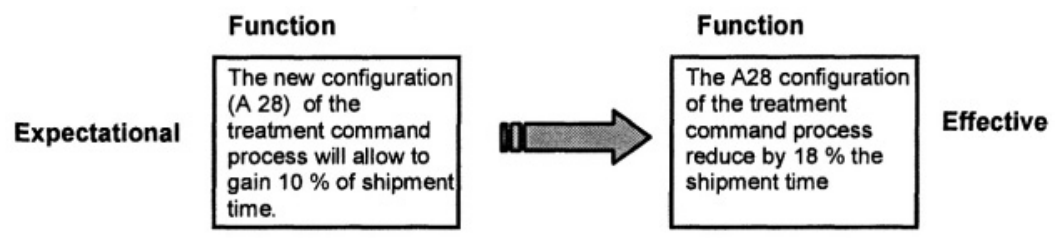

Figure 6 : Evolution of the Expectational knowledge to Effective knowledge

As suggested by some author as Barkema and Vermeulen (1998) cooperation between companies in changing environments helps companies to learn different ways of doing things and to diversify their relationships to jointly develop new technological knowledge (Leonard-Barton, 1995).

All these elements induce the need of a tool to help to create links and community places at multiples levels ensuring a more rapid flow of knowledge and the sharing of different points of views that lead to the creation of new ideas and knowledge. The knowledge classification and its dynamic, that we have presented, is a necessary first step in this direction.

\section{CONCLUSION}

In this paper, we tried to focus on the supply chain structure to better classify the supply chain knowledge. We particularly used some classification criteria as the type, the nature, and the structure. The used classification emphasizes essentially on the explicit knowledge and treat the tacit knowledge management as links to the supply chain actors.

We have introduced in this work, the knowledge dynamic that stressed the importance of the tacit exchange to boost the knowledge creation. These criteria combined with the knowledge dynamic lead to interorganizational learning, resulting in creation of new knowledge and its diffusion through the supply chain. This study is a first step to the design of a web-based supply-chain knowledge tool. Its objective is to facilitate the progressive exchange of knowledge via knowledge network, project teams and knowledge communities in a supply chain context.

\section{REFERENCES}

1. Anand B, Khanna T. Do firms learn to create value? The case of alliances. Strategic Management Journal, 2000; vol.21,3:295-315,.

2. Barkema HG, Vermeulen G. International expansion through start-up or through acquisition: An organizational learning perspective. Academy of Management Journal, 1998; vol.41,1: 7-26. 
3. Buzon L, Bouras A, Ouzrout Y. Representation and exchange of "knowledge cards" : a pen design case study. In the International Journal of Electronic Business. 2003; vol. 1,1: 1-8.

4. Davenport, T. Prusak, L. Working knowledge : How organization manage what they know. Harvard Business School Press, 1998.

5. Dyer, J. 'Specialized supplier networks as a source of competitive advantage: evidence from the auto industry'. Strategic Management Journal, 1996; vol.17, 4: 271-91,.

6. Fensel D, Van Harmelen F, Ding Y, Klein M; Akkermans H, Broekstra J, Kampman A, Van der Meer J, Sure Y, Studer R, Duke A, Davies J, Engels R, Iosif V, Kiryakov A, Lau T, Reimer U and Horrocks I. Ontology-based knowledge management. Computer, 2002; Vol. 11,35 : 56-66.

7. Fong, P. S. W Knowledge creation in multidisciplinary project teams: an empirical study of the processes and their dynamic interrelationships. International Journal of Project Management, 2003; Vol 21,7:479-486,.

8. Gulati, R. Network location and learning: the influence of network resources and firm capabilities on alliance formation. Strategic Management Journal, 1999; vol.20,5:397-420..

9. Hall Richard, Andriani Pierpaolo. Management Focus Analyzing Intangible Resources and Managing Knowledge in a Supply Chain Context. European Management Journal, 1998; vol. 6,6: 685-697,.

10. Huizenga E, Den Hartog J. Concurreren als kennisonderneming. Manager's clout, lente editie, 1998; 18-21.

11. Inkpen, A. Learning, knowledge acquisition, and strategic alliances. Europeean Management journal, 1998, vol. 16,2: 223-229,.

12. Larsson R, Bengtsson L, Henriksson K, Sparks J. The interorganizational learning dilemma: collective knowledge development in strategic alliances. Organization Science, 1998; vol. 9, 3: 285-305.

13. Leonard-Barton D. Wellsprings of knowledge ; building and sustaining the sources of innovation. Boston, MA: Harvard Business School Press, 1995

14. Nonaka I., A Dynamic Theory of Organizational Knowledge Creation , Organization Science, 1995; vol. $5,1: 88-102$.

15. Nonaka, Takeuchi, The knowledge creating company. Oxford University Press, Oxford, 1995.

16. Nonaka I, Konno N. The concept of Ba : building a foundation for knowledge creation. California management review. 1998; vol 40,3:40-54.

17. Ovalle O R, Marquez A C. The effectiveness of using e-collaboration tools in the supply chain: an assessment study with system dynamics. Journal of Purchasing \& Supply Management, 2003; 9 : 151-163..

18. Parenta Michael, Gallupeb Brent, Salisburyc David,. Handelman Jay M. Knowledge creation in focus groups: can group technologies help?. Information \& Management, 2000; 38 :47-58

19. Polanyi M., The Tacit Dimension, Routledge and Kegan Paul, London1, 1969.

20. Romano P. Co-ordination and integration mechanisms to manage logistics processes across supply networks, Journal of Purchasing \& Supply Management. 2003; $9: 119-134$.

21. Taudes Alfred, Trcka Michael, Lukanowicz Martin. Organizational learning in production networks. Journal of Economic Behavior \& Organization,, February 2002; Vo. 47,2:141-163.

22. Wiig, K. Knowledge Management Foundations: Thinking about Thinking - How Organizations Create, Represent and Use Knowledge. Texas, Schema Press, 1993. 